geschrieben - das Original unter dem Titel "Turkey, America's Forgotten Ally" erschien 1987 -, doch ist dies kein Schade, da in Deutschland ganz ähnliche Informationsdefizite über unseren Bündnis- und EG-Assoziationspartner bestehen wie in den USA. Daß Rüstow oft amerikanische Verhältnisse zum Vergleich heranzieht, stört kaum, da diese bei uns relativ gut bekannt sind. Nur wo Rüstow die weitgehende Handlungsunfähigkeit des türkischen Parlaments in den - von einer Militärintervention unterbrochenen - Jahren 1960 bis 1980 ausschießlich auf das damals geltende Verhältniswahlrecht zurückführt (das den Amerikanem immer suspekt war) (S. 89 f. und 95 f.), sind Vorbehalte anzumelden: Ausschlaggebend war die völlig fehlende Gesprächs- und Kooperationsbereitschaft zwischen den Führem der beiden großen Parteien, Ecevit und Demirel. Eine große Koalition zwischen beiden hätte eine solide Regierungsmehrheit ergeben und wäre programmatisch durchaus möglich gewesen. Jedenfalls hatten sie - und haben ihre Nachfolgeparteien - wesentlich mehr gemeinsam als mit den radikalen Randparteien, mit denen beide jeweils kurzlebige Koalitionen bildeten.

Zutreffend bescheinigt Rüstow den türkischen Wählem eine größere politische Reife als vielen Politikern. Die im Anhang aufgelisteten Wahlergebnisse 1950 - 1987 (S. 168 ff) sprechen eine deutliche Sprache. Obsolet sind nur wenige Abschnitte geworden, in denen die Abwehrfunktion der Türkei gegenüber dem sowjetischen Imperialismus hervorgehoben wird. Die Lektüre kann nach wie vor uneingeschränkt empfohlen werden.

Karl Leuteritz

\title{
Dieter Braun
}

\section{Indien als Machtfaktor in Asien.}

Zielsetzungen nach außen, Begrenzungen nach innen.

Stiftung für Wissenschaft und Politik, Forschungsinstitut für internationale Politik und Sicherheit, Ebenhausen, 1990, 108 S., broschiert

Neben einer sich oft vernehmlich und entschieden gebenden außenpolitischen Selbstdarstellung Chinas, die zu einer perzipierten Statur des Landes nicht unwesentlich beigetragen haben mag, ist Indien, wiewohl China in äußeren Dimensionen vielfach ähnlich, international als vergleichsweise nachrangig erschienen.

Der Autor beschreibt das strategische Umfeld Indiens im Wandel - nach den Versuchen einer Wiederannäherung zwischen der Sowjetunion und China sowie dem Ende der sowjetischen Intervention in Afghanistan - und unter den neuralgischen Konstanten - eines nicht zuletzt um Kaschmir konfliktgeladenen Verhältnisses zu Pakistan sowie einer weiter unsicheren Zukunft des indisch-chinesischen Verhältnisses. 
Besonderen Raum widmet der Verfasser der indischen Rüstungspolitik und -industrie. Die beträchtlichen - oft unter hohen volkswirtschaftlichen Kosten erreichten - Erfolge in Nuklear- und Raketentechnik, aber auch die Ausmaße der Rüstungsindustrie insgesamt beschreiben die Konturen eines großen militärorientierten gesellschaftlichen Gefüges: Von 1985-89 rangierte Indien unter den reicheren Entwicklungsländern noch deutlich vor dem Irak und Saudi-Arabien an der Spitze der Importeure von Rüstungsgütern.

In den nicht allein militärisch ausgetragenen ethnisch-religiös komplizierten Konflikten in und um Indien - in Kaschmir und Sri Lanka - half dieser militärische Aufbau, gerade auch der Seestreitkräfte, allerdings wenig, Indiens Umfeld stabil umzuformen, wie die fruchtlose Teilnahme an Befriedungsversuchen in Sri Lanka gezeigt hat. Angesichts innerer Zerrissenheit (Sikhs, Hindus/Moslems) werden die Streitkräfte vielmehr häufig im Land selbst zur einzig funktionierenden Ordnungsmacht.

Militärische Macht steht dabei neben interner Unterentwicklung (Bevölkerungswachstum, Grenzen landwirtschaftlicher Anbaufläche), die bald die Lebensverhältnisse im Land stärker bedrohen wird als äußere Faktoren. Militärisch definierte Bedrohungen beherrschen jedoch weiter die politische Wahmehmung und damit den Fluß wirtschaftlicher Mittel. Die äußeren Ziele militärisch vermittelter Politik werden so von innen konterkariert und begrenzen den "Machtfaktor" Indien.

Gerade diese letzte These des Verfassers hätte mehr Aufmerksamkeit für die über den Bereich der Rüstung hinausragende Wirtschaftspolitik des Landes verdient: Im Zeichen einer nun weniger dirigistischen indischen Ordnungspolitik und um die internen Entwicklungsdefizite nicht sich verschlimmern zu lassen, dürften Ausgaben für Rüstung von sechs Prozent des Bruttosozialprodukts und "die umfangreichste Rüstungsindustrie in der Dritten Welt, mit über 300.000 Beschäftigten, darunter etwa 25.000 Wissenschaftlern und Ingenieuren", kaum länger zu erhalten sein.

Wolfgang Kessler

\section{Joon-Hyung Hong}

Verwaltungsrechtsschutz in der Republik Korea

Studien zum ausländischen öffentlichen Recht, Institut für Völkerrecht der Universität Göttingen, Heft 1

Carl Heymanns Verlag, Köln / Berlin / Bonn / München 1990, 90 S., DM 24,--

Zu Recht hebt Hong eingangs (S. 11/12) den auffälligen Kontrast zwischen der intensiven Beschäftigung mit deutschem Recht in (Süd-)Korea und der nahezu völligen Unkenntnis zumal des koreanischen öffentlichen Rechts in Deutschland hervor, mag diese nun auf dem Nicht-zur-Kenntnis-Nehmen der engen Verflechtungen zwischen deutschem und koreanischem Recht beruhen oder auf der irrigen Vorstellung, dieses sei nur eine unselbständige 